\title{
The effect of physical water quality and water level changes on the occurrence and density of Anopheles mosquito larvae around the shoreline of the Koka reservoir, central Ethiopia
}

\author{
B. M. Teklu ${ }^{1}$, H. Tekie ${ }^{1}$, M. McCartney ${ }^{2}$, and S. Kibret ${ }^{2}$ \\ ${ }^{1}$ Department of Biology, Addis Ababa University, P.O. Box 1176, Addis Ababa, Ethiopia \\ ${ }^{2}$ International Water Management Institute (IWMI), P.O. Box 5689, Addis Ababa, Ethiopia
}

Received: 1 June 2010 - Published in Hydrol. Earth Syst. Sci. Discuss.: 23 August 2010

Revised: 8 December 2010 - Accepted: 12 December 2010 - Published: 16 December 2010

\begin{abstract}
Entomological studies to determine the effect of the physical characteristics of mosquito larval breeding water bodies and reservoir water level changes on the occurrence of Anopheles mosquito larvae were conducted in two villages at Koka reservoir in central Ethiopia between August and December 2007. Of the two study villages, Ejersa is located close to the reservoir, and Kuma is $5 \mathrm{~km}$ away from it. Data on the type, number and physical characteristics of Anopheles larval breeding habitat, species composition and densities of anopheles mosquitoes in and around the study villages were investigated and recorded. Meteorological and reservoir water level data were compared with availability of Anopheles larval breeding sites and densities. Entomological data, derived from weekly larval collections, showed that Anopheles pharoensis Theobald, Anopheles gambiae s.l. Giles, Anopheles coustani Laveran and Anopheles squamosus Theobald were breeding in the study area. The mean larval density of An. gambiae s.l. in this study was higher in slightly turbid and shallow aquatic habitat than in turbid and relatively deep aquatic habitat. The density of An. pharoensis in habitat with floating vegetation and with relatively shady conditions was significantly higher than that of less shaded aquatic habitat and greater emergent vegetation. There was also a positive correlation between the occurrence of Anopheles larvae with the water and daily minimum atmospheric temperature. Similarly at Ejersa, over the sampling period, there was a positive correlation between falling reservoir water levels and the num-
\end{abstract}

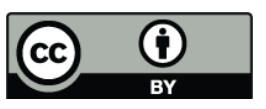

Correspondence to: $\mathrm{B}$. M. Teklu (birhanme@yahoo.com) ber of positive breeding habitats. These results confirm that physical characteristics of the water bodies play an important role in the species composition, total Anopheles larval count, and the density of Anopheles mosquitoes. Suitable breeding habitat in the vicinity of the reservoir village was strongly associated with the reservoir. This is particularly important for An. pharoensis and An. gambiae s.l. which are important vectors of malaria in the area.

\section{Introduction}

In Africa, water resource development activities largely focus on dams and irrigation schemes which contribute substantially to food security, renewable energy production, and sustainable economic development. At present, Ethiopia is engaged in extensive water resource development activities such as construction of dams and reservoirs for irrigation and hydroelectricity (McCartney et al., 2007). The ecologic changes associated with these development activities often entail negative health impacts due to the creation of new mosquito breeding sites and thus altered human-vectorparasite contact patterns. Water impoundments in many malaria endemic parts of the country pose serious public health concerns due to increased risk of malaria transmission (Keiser et al., 2005).

There is an association between malaria incidence and proximity to dams in Ethiopia. Malaria case rates among people living within $1 \mathrm{~km}$ of the Koka reservoir are about 2.9 times greater than for those living between 1 and 2 $\mathrm{km}$ from the reservoir and 19.9 times greater than for those living 5-9 km from the reservoir (Kibret et al., 2009).

Published by Copernicus Publications on behalf of the European Geosciences Union. 
In Tigray malaria incidence in young children was found to be seven times higher in communities near dams than those further away (Ghebreyesus et al., 1999). A recent study in the same area showed that, the abundance of adult Anopheles mosquitoes in villages near dams was 5.9 to 7.2 times higher than those villages further away from dams (Yohannes et al., 2005).

Villages located near dams or impounded waters are thus subjected to increased malaria incidence mainly due to the presence of abundant and suitable breeding habitats for Anopheles mosquitoes which increases the density of the malaria vectors capable of transmitting the disease. Proximity to a dam includes command areas or irrigation water that can serve as Anopheles larval development sites. However, this general expectation is valid only if the habitat conditions created match the ecological requirements of the local vectors. In particular, it requires that the new bodies of standing water have sunlight or shade, surrounding vegetation and turbidity etc. compatible with the larval habitat for at least one local mosquito species (Minakawa et al., 1999; Shililu et al., 2003; Keiser et al., 2005).

This study was conducted to investigate the effect of physical water characteristics of recurrently formed Anopheles larvae breeding habitat, associated with the rise and fall of water in the Koka reservoir in central Ethiopia.

Few previous studies undertaken in Ethiopia have investigated the impact of source reduction activities on malaria transmission (Yohannes et al., 2005). No study to date has specifically investigated the impact of physical water characteristics on species composition and the abundance of Anopheles mosquitoes in association with reservoir water level changes. Understanding the impact of these parameters will lead to better decision making in relation to control activities, since where and how to make interventions will be clearly indicated. Therefore, this study aimed to determine how physical water characteristics, water level changes and other environmental variables, affected the species composition and abundance of Anopheles larvae both close to, and at a distance from, the reservoir shoreline.

\section{Material and methods}

\subsection{Study area}

The Koka dam is located in the Rift Valley of Ethiopia, some $100 \mathrm{~km}$ south east of Addis Ababa in the Awash Basin $\left(8^{\circ} 41^{\prime} \mathrm{N}\right.$ and $\left.39^{\circ} 35^{\prime} \mathrm{E}\right)$ at $1590 \mathrm{~m}$ a.s.l. (Fig. 1). The main rainy season starts in June and extends to the end of $\mathrm{Au}$ gust/September, while the short rainy season occurs from March to May. The mean annual maximum and minimum temperatures are $30.4^{\circ} \mathrm{C}$ and $14^{\circ} \mathrm{C}$, respectively.

The dam was the first hydropower plant to generate electricity for Addis Ababa and other urban centers. However, it is now multipurpose and, in addition to electricity produc-

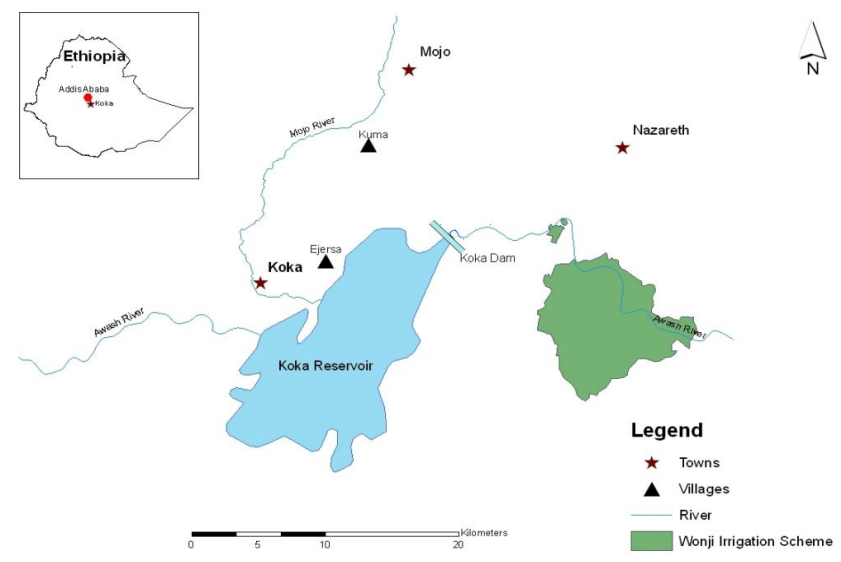

Fig. 1. Map of the Koka area in the middle course of the Ethiopian Rift Valley (Triangles show the study villages). (Courtesy: International Water Management Institute (IWMI), Addis Ababa, Ethiopia).

tion it is also used for downstream irrigation of the 6000 ha Wonji Sugarcane Project (McCartney et al., 2007). The capacity of the Koka reservoir has declined from $1650 \mathrm{Mm}^{3}$ in 1959 to $1186 \mathrm{Mm}^{3}$ due to sedimentation over the years. The loss of total storage capacity is estimated to be $464 \mathrm{Mm}^{3}$, which is $28.1 \%$ of the total storage volume of the reservoir (Zewdu, 2005).

The area is characterized by a wide and open plain, suitable for cultivation of agricultural crops. Vegetables are grown around the reservoir in the wetland created by the receding reservoir water, using diesel water pumps to extract the shallow ground water. Sparsely distributed acacia trees are common in the area.

The study was conducted at two sites located at different distances from the Koka reservoir. Ejersa (population 2380) is a reservoir village where the reservoir comes close to the middle of the village during the peak of the rainy season. Kuma (population 4300), the control village is located five $\mathrm{km}$ from Ejersa and is always at least $7 \mathrm{~km}$ away from the reservoir, even when it is at its maximum extent. Both villages are located at a similar elevation (i.e. $1590 \mathrm{~m}$ a.s.l.). In both villages people live in traditional houses or huts called Tukuls.

In Ejersa, there are households that are located only a few meters away from the shore during the rainy season when the reservoir water levels rise. Farmers in the area produce vegetables and some cereals especially between the months July and February. Residents also fish in the reservoir during the rainy season. As the water recedes during the dry season they cultivate the land with potential mosquito larval breeding sites, in the form of turbid shoreline puddles, rain pools and irrigation ditches (Plates 1 and 2).

Ten years of monthly climate data as well as the most recent two years of mean daily data were obtained from the National Meteorological Agency (NMA) (Fig. 2). These data 


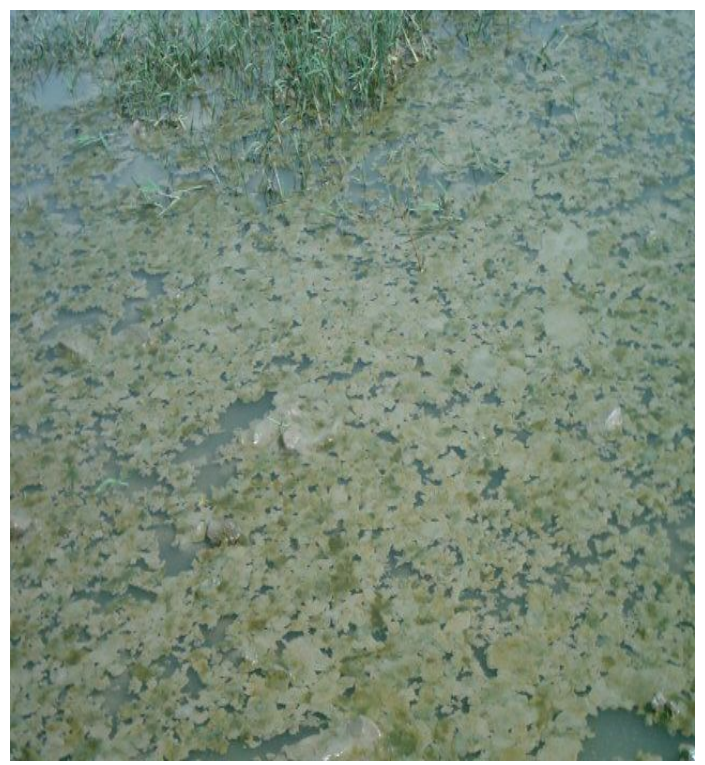

Plate 1. Turbid shoreline puddle with floating aquatic vegetation: an ideal breeding site for An. pharoensis in Ejersa, a village around the Koka reservoir.

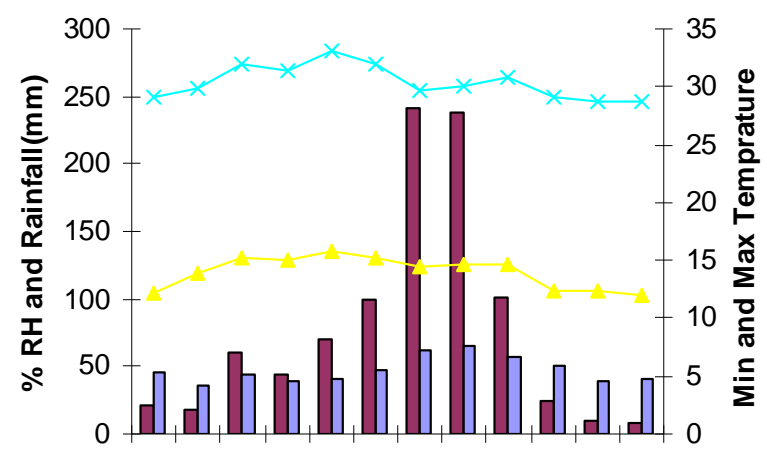

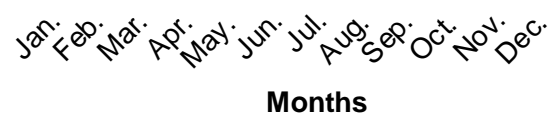

Rainfall $(\mathrm{mm}) \sqsubset \% \mathrm{RH} \backsim$ Min temp $\longleftarrow$ Max temp

Fig. 2. Monthly mean maximum and minimum temperature $\left({ }^{\circ} \mathrm{C}\right)$, relative humidity and rainfall $(\mathrm{mm})$ of the Koka Dam (19982007). (Courtesy: National Meteorological Agency, Addis Ababa, Ethiopia).

comprised observations of minimum and maximum temperature, rainfall and relative humidity. Daily reservoir water levels for the study period were obtained from the Ethiopian Electric Power Corporation (EEPCo).

\subsection{Larval sampling}

Larval collection was done weekly in the two study villages over the period August-December, 2007. This period was

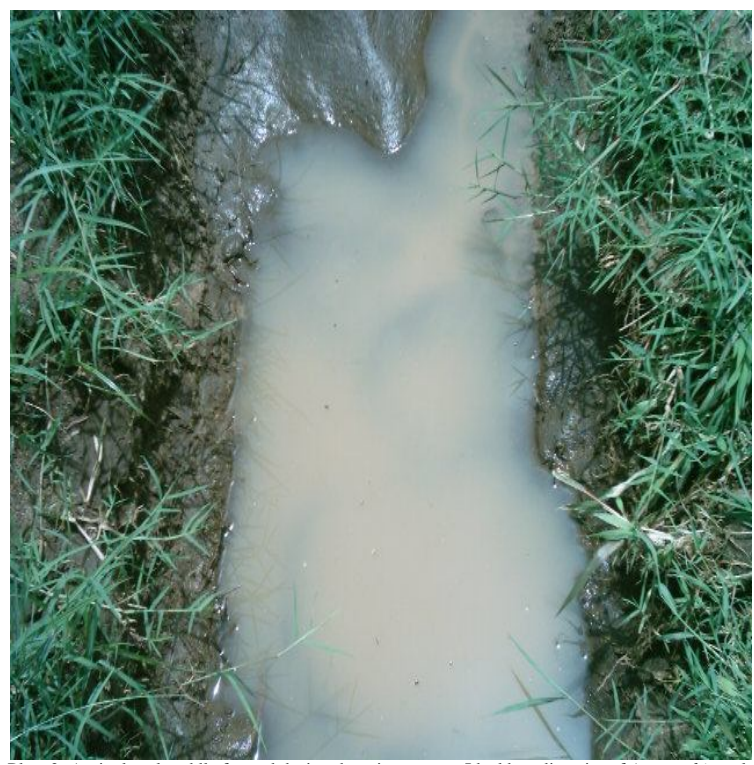

Plate 2. Agricultural puddle formed during the rainy season: Ideal breeding site of An. gambiae s.l. at Kuma village, located $5 \mathrm{~km}$ away from the shoreline of the Koka dam.

selected because it corresponds to the peak of malaria transmission in the area (Abose et al., 1998; Kibret et al., 2009). During each sampling, the entire available breeding habitat within a $500 \mathrm{~m}^{2}$ area was visited and checked for the presence of Anopheles mosquito larvae. In all potential breeding sites, 3 samples were obtained using a standard $(350 \mathrm{ml})$ dipper. Any larvae collected were pipetted into separate vials and taken to the Nazereth Malaria Control Center Laboratory where they were gently heated to kill the larvae and preserved in a $70 \%$ alcohol solution, prior to identification. The third and fourth instar larvae were visually sorted and processed for identification. The larvae were first mounted (using a gum chloral) on a dissecting microscope and later identified to the species level using morphological characteristics (Verrone, 1962).

\subsection{Larval habitat characterization}

Along with the collection of anopheline larvae, data on the characteristics of the larval breeding habitats were collected. For each positive habitat identified, water temperature was measured using a thermometer. It was lowered below the water surface and left for two minutes for the thermometer reading to stabilize. It was then withdrawn without touching the bulb end and the temperature was recorded (Minakawa et al., 1999; Shillilu et al., 2003; Yohannes et al., 2005). The turbidity of the larval breeding water was categorized by taking a small sample of water in a glass test tube and comparing it with a white background. Turbidity was classified as simply "turbid" or "slightly turbid". Water depth was measured with a small-labeled stick. Other parameters, including 
Table 1. Anopheles larval count in different types of breeding habitats in the two study sites during the study period (AugustDecember 2007).

\begin{tabular}{|c|c|c|c|c|c|c|c|}
\hline \multirow[b]{2}{*}{ Village } & \multirow[b]{2}{*}{ Type of breeding site } & \multirow[b]{2}{*}{ no. positive } & \multicolumn{5}{|c|}{ Number of Anopheles larvae collected* } \\
\hline & & & An. gambiae s.l. & An. pharoensis & An. coustani & An. squamosus & Total \\
\hline \multirow[t]{4}{*}{ Ejersa } & Shoreline puddles & 66 & $212(17.4)$ & $926(76.0)$ & $53(4.4)$ & $27(2.2)$ & 1218 \\
\hline & Rain pools & 23 & $208(67.3$ & $90(29.1)$ & $2(0.6)$ & $9(2.9)$ & 326 \\
\hline & Agricultural puddles & 8 & $56(47.5)$ & $59(50.0)$ & $1(1.0)$ & $2(2.0)$ & 101 \\
\hline & Total & 97 & $476(28.9)$ & $1075(65.3)$ & $56(3.4)$ & $38(2.3)$ & 1645 \\
\hline \multirow[t]{4}{*}{ Kuma } & Shoreline puddles & 0 & NA & NA & NA & NA & NA \\
\hline & Rain pools & 16 & $95(83.3)$ & $17(14.9)$ & $2(1.8)$ & $0(0)$ & 114 \\
\hline & Agricultural puddles & 6 & $33(86.8)$ & $5(13.2)$ & $0(0)$ & $0(0)$ & 38 \\
\hline & Total & 22 & $128(84.2)$ & $22(14.5)$ & $2(0)$ & $0(0)$ & 152 \\
\hline
\end{tabular}

* Values in parenthesis are percentages of total larvae collected at each type of breeding habitat. $\mathrm{NA}=$ not available.

surface area, exposure to sunlight, presence and types of vegetation and type of substratum (i.e. muddy or rocky) were observed and recorded (Minakawa et al., 1999; Shillilu et al., 2003; Yohannes et al., 2005).

\subsection{Data analysis}

All the data were entered into Microsoft Excel and analyzed using SPSS version 13 statistical software (SPSS Inc, Chicago, IL, USA). The Chi-square test was used to compare total number of larvae in different types of aquatic habitat and an independent sample t-test was used to analyze the relationship between mean larval densities and different physical characteristics of the habitat. Weekly changes in reservoir water levels were computed by subtracting the value of the water level at the start of the week from that at the end of the week. Descriptive statistics and bivariate correlations were used to determine the strength of association between larval density and the independent variables including atmospheric temperature ( $\min$ and $\max$ ), water temperature and reservoir water level.

\section{Results}

\subsection{Larval species composition}

The number of positive sites encountered throughout the sampling period was 97 for the reservoir village and 22 for the non-reservoir village. At Ejersa 66 (i.e. 68\%) of the breeding habitat was shoreline puddles. In contrast, rain pools dominated (i.e. 83.3\%) at Kuma.

A total of 1797 mature larvae of Anopheles mosquitoes were collected from both study villages during the study period. Of these 1645 (91.4\%) were from Ejersa and 152 (8.6\%) were from Kuma. An. pharoensis Theobald An. gam- biae s.l. Giles presumably An. arabiensis (Abose et al., 1998), An. coustani Laveran and An. squamosus Theobald constitute the anopheline fauna in the study area (Table 1).

Significantly higher numbers of both An. gambiae s.l. $\left(X^{2}=200.5, \quad \mathrm{df}=1, p<0.05\right)$ and An. pharoensis $\left(X^{2}=942.8, \mathrm{df}=1, p<0.05\right)$ were found at Ejersa than at Kuma.

\subsection{Larval density and habitat preference in the two villages}

At Ejersa, of the total 1645 mature larvae, 1218 (74\%) were collected from shoreline puddles. These comprised 212 (17.4\%) An. gambiae s.1., 926 (76.0\%) An. pharoensis, 53 (4.4\%) An. coustani and 27 (2.2\%) An. squamosus. Shoreline puddles were the main habitat for the breeding of An. pharoensis in Ejersa. In Kuma, the most common breeding habitat was seasonal rain pools and agricultural puddles (Table 1).

\subsection{Density of Anopheles larvae at different sampling periods}

In Ejersa, the peak larval density of An. pharoensis was recorded in mid October (9th sampling week) (50 larvae/100 dips). At Kuma, the highest larval density of An. gambiae s.l. was also recorded in mid October (8th sampling week) (33.5 larvae/100 dips) (Fig. 3).

\subsection{Turbidity, depth, vegetation, intensity of shade and larval density}

The combined data on mean larval density from Ejersa and Kuma showed that An. gambiae s.l. was greater in slightly turbid and shallow aquatic habitat than in turbid and deep aquatic habitat $(F=16.97, p<0.05$ and $F=6.03, p<0.05$ ). 


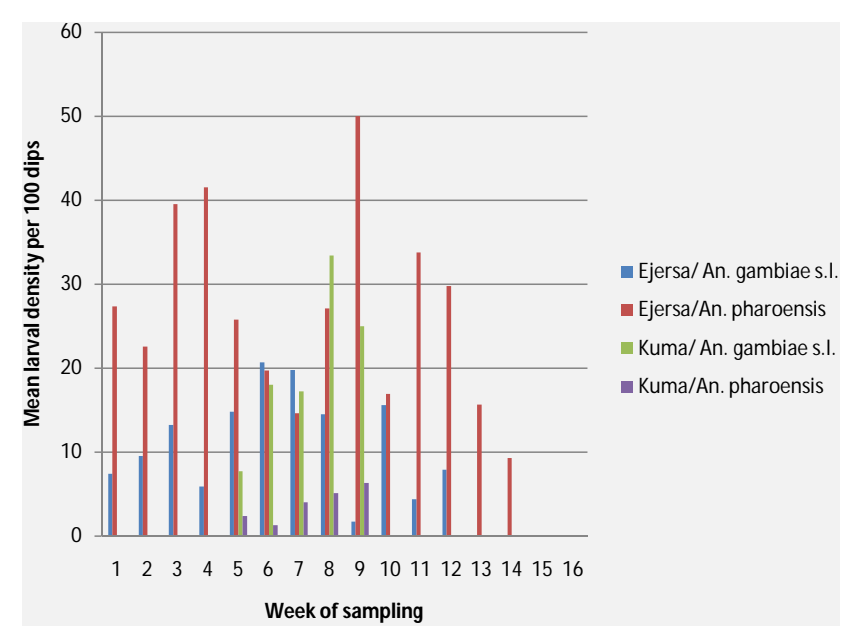

Fig. 3. Mean number of larvae (Number of larvae/100 dips) of An. gambiae s.l. and An. pharoensis for the villages of Ejersa and Kuma ( $n=16$ surveys).

In contrast, the density of An. gambiae s.l. larvae was greater in habitat with emergent aquatic vegetation and relatively open sunlit conditions $(F=11.14, p<0.05$ and $F=10.77$, $p<0.05$ ) (Table 2).

The mean larval density of An. pharoensis in turbid aquatic habitat was found to be significantly higher than that of slightly turbid aquatic habitat $(F=13.82, p<0.05)$. The density of An. pharoensis in aquatic habitat with floating vegetation and with relatively shady conditions was significantly higher than that of the aquatic habitat with more light and more emergent vegetation $(F=15.75, p<0.05$ and $F=10.56, p<0.05)$. Depth of larval habitat had no significant effect on the mean larval density of An. pharoensis in the study area $(F=0.84, p>0.05)$ (Table 2$)$.

\subsection{Larval breeding water temperature, water level and larval density}

In this study, the water temperature recorded throughout the study period ranged between $18^{\circ} \mathrm{C}$ and $27.2^{\circ} \mathrm{C}$ for breeding habitat at Ejersa, and between $22.5^{\circ} \mathrm{C}$ and $25.5^{\circ} \mathrm{C}$ at Kuma (Table 3). The water temperature of the larval breeding sites was entirely dependent on the variation in the atmospheric temperature. The reservoir water level increased at the start of the sampling period with the highest water level recorded in mid September $(110.6 \mathrm{~m}$ above local datum). Subsequently it fell, reaching a minimum at the end of sampling period in December (108.8 $\mathrm{m}$ above local datum). At Ejersa, the number of positive breeding sites dropped to zero by mid-December (during the 15th sampling week) even though the number of potential breeding sites (i.e. shoreline puddles) was actually increasing (Fig. 4).

Weekly changes in water level of the Koka reservoir had a positive correlation with the number of positive larval habitats at Ejersa $\left(r^{2}=0.34, p<0.05\right)$ (i.e. as reservoir wa-

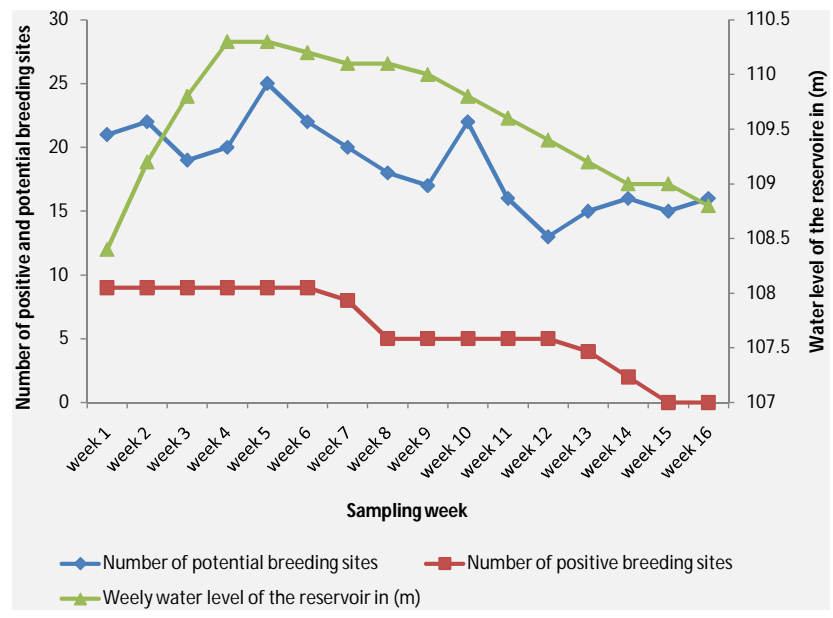

Fig. 4. Water Level (m) of the Koka reservoir, number of positive breeding sites, and number of potential breeding sites (AugustDecember 2007).

ter levels fell the number of positive sites decreased). No correlation existed between weekly change in water level (m) and the number of potential breeding habitats observed $\left(r^{2}=0.19, P>0.05\right)$. Absolute water level $(\mathrm{m})$ of the Koka reservoir indicated no correlation with the number of neither positive breeding habitats nor potential breeding habitats $\left(r^{2}=0.16, p>0.05\right.$ and $\left.r^{2}=0.22, p>0.05\right)$.

\subsection{Meteorological variables and larval breeding activity of Anopheles mosquitoes}

At Ejersa, the minimum atmospheric temperature was found to be slightly positively correlated with the densities of both An. gambiae s.l. and An. pharoensis $\left(r^{2}=0.29\right.$ and 0.26 , $p<0.05$ ) (Table 4). At Kuma only rainfall showed a positive correlation with mean larval density of An. pharoensis $\left(r^{2}=0.33, p<0.05\right)$, while no correlation existed between the remaining meteorological variables and mean larval density of An. gambiae s.l. and An. pharoensis (Table 4).

\section{Discussion}

The major finding of this study is that both species diversity and abundance are significantly greater in the village located close to the reservoir than they are in the village further away. The larvae of the two major malaria vectors in the area were found in much greater numbers in the reservoir village than in the control village. Both the physical water quality of the breeding habitat and the surrounding environmental factors (especially minimum and maximum daily atmospheric temperature) affect the breeding of malaria mosquitoes.

The occurrence of An. pharoensis larvae in Ejersa was significantly higher than in Kuma. The major reason for this was that the reservoir site provided shoreline puddles suitable for 
Table 2. Physical habitat characteristics and mean larval density (no. of larvae per 100 dips) of An. gambiae s.l. and An. pharoensis in Ejersa.

\begin{tabular}{|c|c|c|c|c|c|}
\hline \multirow[b]{2}{*}{ Species } & \multirow{2}{*}{$\begin{array}{l}\text { Habitat } \\
\text { Characteristics }\end{array}$} & & \multicolumn{3}{|c|}{ Number of larvae per 100 dips } \\
\hline & & & Mean $\pm \mathrm{SE}$ & $\mathrm{F}$ & $\mathrm{P}$ \\
\hline \multirow[t]{8}{*}{ An. gambiae s.l. } & Turbidity & Turbid & $5.55 \pm 0.25$ & 16.97 & $0^{* *}$ \\
\hline & & Slightly turbid & $20.13 \pm 0.46$ & & \\
\hline & Depth $^{\dagger}$ & Deep & $8.55 \pm 0.5$ & & \\
\hline & & Shallow & $15.54 \pm 0.47$ & 6.03 & $0.02^{*}$ \\
\hline & Vegetation & Emergent & $23.31 \pm 0.67$ & 11.14 & $0.001^{* *}$ \\
\hline & & Floating & $6.93 \pm 0.41$ & & \\
\hline & Intensity of shade & Light & $19.64 \pm 0.46$ & 10.77 & $0.001^{* *}$ \\
\hline & & Shade & $6.09 \pm 0.29$ & & \\
\hline \multirow{8}{*}{ An. pharoensis } & Turbidity & Turbid & $32.37 \pm 1.11$ & 13.82 & $0^{* *}$ \\
\hline & & Slightly turbid & $12.2 \pm 0.85$ & & \\
\hline & $\operatorname{Depth}^{\dagger}$ & Deep & $21.34 \pm 1.46$ & 0.84 & 0.363 \\
\hline & & Shallow & $24.03 \pm 0.96$ & & \\
\hline & Vegetation & Emergent & $10.08 \pm 0.88$ & 15.75 & $0^{* *}$ \\
\hline & & Floating & $31.11 \pm 1.01$ & & \\
\hline & Intensity of shade & Light & $12.86 \pm 0.9$ & 10.56 & $0.002^{* *}$ \\
\hline & & Shade & $31.56 \pm 1.11$ & & \\
\hline
\end{tabular}

** Significant at $p<0.01,{ }^{*}$ Significant at $p<0.05$

$\dagger$ Aquatic habitats $<0.25 \mathrm{~cm}$ in depth are categorized as shallow and those $>0.25 \mathrm{~cm}$ in depth are categorized as deep.

the breeding of this species. Previous studies have shown that Anopheles gambiae s.l. prefers open, shallow and temporary breeding habitat (Coeteez et al., 2002) while An. pharoensis flourishes in shaded, permanent water bodies with large vegetated areas, characterized by floating plants (Gillies and De Mellion, 1968; Carrara et al., 1990).

Shoreline puddles are turbid by nature and have lots of aquatic vegetation floating in them. Such habitat may exist for a considerable period of time because they are created in areas where the ground water level is close to the surface and this increases the longevity of the puddles (Fillinger et al., 2004). The size of such puddles is much greater and typically they are deeper than the rain pools and agricultural puddles (Keiser et al., 2008). This result is consistent with others in northern Ethiopia (Yohannes et al., 2005) and others at Koka that have shown villages located close to the reservoir were characterized by significant numbers of shoreline puddles whilst control villages were characterized by fewer and less extensive breeding sites, created mainly by rainfall (Kibret et al., 2009).

Generally mean larval density of An. gambiae s.l. was greater in slightly turbid and shallow aquatic habitat than in turbid and deep aquatic habitat. Similarly larval density of An. gambiae s.l. was greater in habitat with emergent aquatic vegetation and with relatively open sunlit conditions. Many of the rain pools and agricultural puddles were characterized by slightly turbid conditions with muddy substrate. These breeding sites were ephemeral and tended to dry in a relatively short period of time. This result is consistent with past observations that An. gambiae s.l. prefers breeding habitat with relatively less shade, muddy substrate and slight turbidity (Minakawa et al., 1999). In such a microenvironment, the soil substrate provides nutrients for the enrichment of bacteria that serve as a food source for larvae, and possibly as oviposition attractants.

The mean larval density of An. pharoensis in turbid aquatic habitat was significantly higher than in that with slightly turbid conditions. The major reason for this was that An. pharoensis prefers turbid aquatic breeding habitat (Gillies and De Mellion, 1968; Carrara et al., 1990). The density of An. pharoensis in aquatic habitat with floating vegetation and with relatively shady conditions was found to be higher than that of aquatic habitat with more light and greater emergent vegetation. The depth of puddles made no difference to the mean larval density of An. pharoensis.

These results confirm that the colonization of habitat by specific species of local Anopheles larvae is to a large extent governed by the physical characteristics of that habitat. Similar studies conducted in Eritrea indicated that turbidity, depth of puddle and water current were the physical parameters that made a significant difference in mean larval abundance (Shililu et al., 2003). These physical characteristics were also reported to bring about significant variation in mean larval density in different aquatic habitat (Jacob et al., 2005).

In this study, minimum atmospheric temperature was found to be positively correlated with mean larval density of An. pharoensis and An. gambiae s.l. at Ejersa but not at Kuma. Water temperature was found to be strongly positively correlated with mean larval density of the two dominant species, An. pharoensis and An. gambiae s.l. at Ejersa. 
Table 3. Mean water temperatures and larval density of An. gambiae s.l. and An. pharoensis in different sampling interval during the study period (August-December 2007).

\begin{tabular}{|c|c|c|c|c|c|c|}
\hline \multirow[b]{3}{*}{$\begin{array}{r}\text { Sampling } \\
\text { weeks }\end{array}$} & \multicolumn{3}{|c|}{ Ejersa } & \multicolumn{3}{|c|}{ Kuma } \\
\hline & \multicolumn{3}{|c|}{ Mean larval Density Per 100 Dips } & \multicolumn{3}{|c|}{ Mean larval Density Per 100 Dips } \\
\hline & Water $\mathrm{T}^{0}$ & An. gambiae s.1. & An. pharoensis & Water $\mathrm{T}^{0}$ & An. gambiae s.l. & An. pharoensis \\
\hline 1 & 20.22 & $7.4 \pm 1.0$ & $27.37 \pm 3.7$ & $(-)$ & $(-)$ & $(-)$ \\
\hline 2 & 24.44 & $9.5 \pm 1.1$ & $22.54 \pm 3.0$ & $(-)$ & $(-)$ & $(-)$ \\
\hline 3 & 25.11 & $13.2 \pm 1.3$ & $39.5 \pm 4.7$ & $(-)$ & $(-)$ & $(-)$ \\
\hline 4 & 23.11 & $5.9 \pm 0.9$ & $41.5 \pm 2.8$ & $(-)$ & $(-)$ & $(-)$ \\
\hline 5 & 23.8 & $14.8 \pm 1.8$ & $25.8 \pm 2.7$ & 22.5 & $7.7 \pm 0.2$ & $2.4 \pm 0.4$ \\
\hline 6 & 25.73 & $20.7 \pm 1.2$ & $19.70 \pm 2.5$ & 23.4 & $18.0 \pm 0.8$ & $1.30 \pm 0.2$ \\
\hline 7 & 21 & $19.8 \pm 1.4$ & $14.6 \pm 2.1$ & 25.5 & $17.2 \pm 1.2$ & $4.0 \pm 0.6$ \\
\hline 8 & 23 & $14.5 \pm 0.7$ & $27.1 \pm 1.6$ & 23.6 & $33.4 \pm 2.7$ & $5.1 \pm 0.9$ \\
\hline 9 & 26.33 & $1.7 \pm 0.2$ & $50.0 \pm 1.3$ & 24.3 & $25.0 \pm 1.4$ & $6.3 \pm 0.5$ \\
\hline 10 & 27.2 & $15.6 \pm 0.6$ & $16.9 \pm 0.8$ & $(-)$ & $(-)$ & $(-)$ \\
\hline 11 & 26.2 & $4.4 \pm 0.8$ & $33.8 \pm 0.9$ & $(-)$ & $(-)$ & $(-)$ \\
\hline 12 & 18.2 & $7.9 \pm 0.2$ & $29.8 \pm 0.7$ & $(-)$ & $(-)$ & $(-)$ \\
\hline 13 & 18 & $(-)$ & $15.63 \pm 0.8$ & $(-)$ & $(-)$ & $(-)$ \\
\hline 14 & 18 & $(-)$ & $9.3 \pm 0.5$ & $(-)$ & $(-)$ & $(-)$ \\
\hline 15 & $(-)$ & $(-)$ & $(-)$ & $(-)$ & $(-)$ & $(-)$ \\
\hline 16 & $(-)$ & $(-)$ & $(-)$ & $(-)$ & $(-)$ & $(-)$ \\
\hline
\end{tabular}

(-) Indicates no temperature reading since there was no positive breeding habitats.

According to Shililu et al. (2003), water temperature was positively correlated to larval density in Eritrea $\left(r^{2}=0.03\right.$, $P<0.01)$. Studies conducted on water temperature preference indicate that An. gambiae s.l. is tolerant to relatively high water temperatures (McCrae, 1983; Minakawa et al., 1999). In open sunlit rain pools water temperature sometimes reaches $40^{\circ} \mathrm{C}$. The larvae of An. gambiae s.l. have the capacity to survive and may even develop more rapidly as the water temperature increases. This might be because higher temperatures encourage better development of eggs or warmer water temperatures allow the development of more microorganisms that are used for food by the larvae (McCrae, 1983; Minakawa et al., 1999).

By the end of the study period all the breeding sites in Kuma were dry and at Ejersa only relatively new shoreline puddles remained. For this reason almost all the breeding sites visited were negative for anopheline larvae. The sharp decrease in the atmospheric temperature of the area, in association with windy conditions, which might prevent adult mosquitoes from reaching the shoreline puddles to lay eggs, possibly explain the absence of anopheline larvae in the remaining breeding sites.

Another study conducted at Koka has indicated that the abundance of Anopheles larvae along the reservoir shoreline is affected by water level changes, with faster rates of reservoir recession resulting in reduced abundance (Kibret el al., 2009). In the current study, a similar finding was made: weekly water level changes were found to be positively cor- related with the number of positive breeding habitats. As water levels fell the amount of positive breeding habitat also decreased. This was despite the fact that, though not statistically significant, the amount of potential breeding habitat increased as water levels dropped. This confirms that the presence of suitable breeding habitat is not the only factor determining the presence of larvae. Climatic and other environmental variables also play a major role in determining the abundance of anopheline larvae.

\section{Conclusions}

In this study, physical water quality was found to be an important factor in variation in the abundance and species composition of Anopheles larvae. Reservoir water level changes were the main reason for the creation of potential breeding habitats (i.e. shore line puddles) in the reservoir village. However, both water and atmospheric temperature fluctuations were also found to be important sources of differences in larval density over time.

Three major Anopheles mosquitoes breeding habitats were identified: shoreline puddles, rain pools and agricultural puddles. Shoreline puddles were the major type of breeding habitat in the reservoir village.

The occurrence of An. pharoensis and An. gambiae s.l., principal vectors of malaria in Ethiopia, in the reservoir village was much higher than in the non-reservoir village 
Table 4. Correlation between abundance of An. gambiae s.l. and An. pharoensis with daily mean atmospheric temperature $\left({ }^{\circ} \mathrm{C}\right)$, atmospheric minimum and maximum temperature $\left({ }^{\circ} \mathrm{C}\right)$ and total rainfall $(\mathrm{mm})$ at Ejersa and Kuma.

\begin{tabular}{|c|c|c|c|c|c|}
\hline & & \multicolumn{2}{|c|}{ An. gambiae } & \multicolumn{2}{|c|}{ An. pharoensis } \\
\hline & & $r^{2}$ value & $p$ value & $r^{2}$ value & $P$ value \\
\hline \multirow[t]{4}{*}{ Ejresa } & Daily mean temperature & 0.20 & 0.079 & 0.20 & 0.079 \\
\hline & Min. atm. temperature & 0.29 & $0.030^{*}$ & 0.26 & $0.044^{*}$ \\
\hline & Max. atm. temperature & 0.00 & 0.902 & 0.02 & 0.592 \\
\hline & Total rainfall & 0.09 & 0.234 & 0.09 & 0.234 \\
\hline \multirow[t]{4}{*}{ Kuma } & Dailey mean temperature & 0.02 & 0.604 & 0.00 & 0.838 \\
\hline & Min. atm. temperature & 0.03 & 0.516 & 0.03 & 0.488 \\
\hline & Max. atm. temperature & 0.00 & 0.939 & 0.04 & 0.483 \\
\hline & Total rainfall & 0.33 & $0.020^{*}$ & 0.15 & 0.135 \\
\hline
\end{tabular}

* Significant at $p<0.05$.

mainly because of the availability of shoreline puddles suitable for breeding. The occurrence of An. gambiae s.l. was also greater than that of the non-reservoir village in which the effect of the dam was not observable.

The occurrence of An. pharoensis was greater in turbid aquatic habitat with floating vegetation. These were the principal characteristics of the shoreline puddles. Anopheles gambiae s.l. occurred in shallow slightly turbid habitat with emergent vegetation and open sunlit conditions.

The species diversity, chemical habitat characteristics, water holding capacity of the soil and longevity of breeding habitats need to be thoroughly investigated in the future to generate detailed baseline data which will serve as a basis for proper water management activities for malaria risk mitigation.

Acknowledgements. This work was supported in part by the Challenge Program for Water and Food, a program of the Consultative Group for International Agricultural Research. The authors are grateful to the Oramia Health Authority for the use of facilities at the Nazareth Malaria Control Centre. They are also grateful to the Ethiopian Electric Power Corporation and the Ethiopian National Meteorological Agency for the provision of data.

Edited by: M. Gebremichael

\section{References}

Abose, T., Ameneshewa, B., Teklehaimanot, A., Tulu, A., Colluzi, M., Petrarca, V., and Petrangeli, G.: Cytogenetic studies on the Anopheles gambiae complex species in Ethiopia, Ethiopian Journal of Health Development, 12, 81-83, 1998.

Carrara, G., Petratca, V., Niang, M., and Coluzzi, M.: Anopheles pharoensis and transmission of Plalsmodium falciparum in the Senegal River delta, West Africa, Med. Vet. Entomol., 4, 421424, 1990.

Cotezee, M., Coaig, M., and Sueur, D.: Distribution of Africa malaria mosquitoes belonging to the Anopheles gambiae complex, Parasitology Today, 16, 74-77, 2002.
Fillinger, U., Sonye, G., Killin, F., Knols, B., and Becker, N.: The practical importance of permanent and semi permanent habitats for controlling aquatic stages of Anopheles gambiae s.1. mosquitoes: operational observation from a rural town in western Kenya, Tropical Medicine and International Health, 9, 1274-1289, 2004.

Ghebreyesus, T., Haile, M., Witten, K., Getachew, A., Yohannes, A., Yohannes, M., Teklehaimanot, H., and Lindsay, S.: Incidence of malaria among children living near dams in northern Ethiopia: Community based incidence survey, British Medical Journal, 319, 663-666, 1999.

Gillies, M. and De Meillon, B.: The Anopheline of Africa South of the Sahara. Johannesburg: Publications of South Africa Institute of Medical Research, South Africa, pp. 343, 1968.

Jakob, B., Kristopher, Arheart, K., Griffith, D., Mbogo, C., Githeko, A., Regens, J., Githure, J., Novak, R., and Beier, J. : Evaluation of Environmental Data for Identification of Anopheles (Diptera: Culicidae) Aquatic larval habitats in Kisumu and Malindi, Kenya, Entomological Society of America, 42, 751-755, 2005.

Keiser, J., Castro, D., and Maltese, M.: Effect of irrigation and large dams on the burden of malaria on a global and regional scale, Am. J. Trop. Med. Hyg., 72, 392-406, 2005.

Kibret, S., McCartney, M. P., Lautze, J., and Jayasinghe, G.: Malaria transmission in the vicinity of impounded water: evidence from the Koka reservoir, Ethiopia, Colombo, Sri Lanka: International Water Management Institute (IWMI Research Report 132), 47 pp., 2009.

Kibret, S.: Entomological studies on the impact of a small-scale irrigation scheme on malaria transmission around Ziway, Central Ethiopia, M sc Thesis, Addis Ababa University, 87 pp., 2008.

Kondrachine, A. and Trigg, P.: Global overview of malaria, Indian J. Med. Res., 106, 39-52, 1997.

McCartney, M., Awulachew, S., Seleshi, Y., Prasad, K., King, J., and Tarekegn, D.: Decision support systems for dam planning and operation in Africa, IWMI Working Paper 119, Colombo, Srilanka: International Water Management Institute, $47 \mathrm{pp}$, 2007.

McCrae, A.: Oviposition by African malaria vectors, 1. Temporal activity patterns of caged, wild caught, fresh water An. gambiae 
Giles s.l., Ann. Trop. Med. Parasit., 77, 615-625, 1983.

Minakawa, N., Mutero, C., Githure, J., Beier, J., and Yan, G.: Spatial distribution and habitat characterization of Anopheline mosquito larvae in Western Kenya, American Society of Tropical Medicine and Hygiene, 61, 1010-1016, 1999.

Robert, V., Awano, H., and Thioulouse, J.: Ecology of larval mosquitoes, with special reference to Anopheles arabiensis (Diptera: Culisidae) in Market- Garden Wells in Urban Dakar, Senegal, Entomological Society of America, 35, 948-955, 1998.

Shillilu, J., Gebremeskel, T., Seulu, F., Mengistu, S., Fekadu, H., Mehari, Z., Gebregziabiher, A., Sintasath, D., Bretas, G., Mbongo, C., John, G., Brantly, E., Novak, R., and Beier, J.: Larval habitat diversity and ecology of anopheline larvae in Eritrea, J. Med. Entomol., 40, 921-929, 2003.
Verrone, G.: Outline for the determination of malarial mosquitoes in Ethiopia, Anopheline larvae, Mosquito News, 22, 394-401, 1962.

Yohannes, M., Haile, M., Ghebreyesus, T., Witten, K. Getachew, A., Byass, P., and Lindsay, S.: Can source reduction of mosquito larval habitat reduce malaria transmission in Tigray Ethiopia, Tropical Medicine and International Health, 10, 1274-1285, 2005.

Zewdu, T.: Dam safety Evaluation on Koka dam, Ethiopia, M sc Thesis, Addis Ababa University, 65 pp., 2005. 